\title{
Scaling Up to Tackle Low Levels of Urban Food Waste Recycling
}

\section{KATIE SEABORN}

Tokyo Institute of Technology

University College London, UCLIC

\section{JOHANNA MÄHÖNEN}

University College London, UCLIC

\section{YVONNE ROGERS}

University College London, UCLIC

CITATION: Seaborn, K., Mähönen, J. \& Rogers, Y. (2020). Scaling up to tackle low levels of urban food waste recycling. Proceedings of the 2020 ACM International Conference on Designing Interactive Systems (DIS '20), pp. 1327-1340. Eindhoven, The Netherlands: ACM. https://doi.org/10.1145/3357236.3395524

(c) Seaborn, Mähönen, and Rogers 2020. This is the authors' version of the work. It is posted here for your personal use. Not for redistribution. The definitive version was published in DIS '20, https://doi.org/10.1145/3357236.3395524. 


\section{Scaling Up to Tackle Low Levels of Urban Food Waste Recycling}

\author{
Katie Seaborn ${ }^{1}$ \\ Tokyo Institute of Technology \\ Tokyo, Japan \\ seaborn.k.aa@m.titech.ac.jp
}

\author{
Johanna Mähönen \\ University College London \\ London, UK \\ j.mahonen.16@ucl.ac.uk
}

\author{
Yvonne Rogers \\ University College London \\ London, UK \\ y.rogers@ucl.ac.uk
}

\begin{abstract}
Addressing societal problems is complex; little is known about which paths or approaches are successful. We discuss what is involved in knowing when and how and for whom change needs to occur, as well as the impact of doing so at scale - especially when novelty and academic contributions may be compromised. To this end, we present a 'scaling up' framework based on a societal project where we worked with multiple stakeholders to improve food waste recycling rates in a housing estate. We propose three main factors involved in scaling up: (i) 'the people,' through reimagining roles and relationships, (ii) 'the method,' requiring flexibility in design and research, and (iii) 'the impact,' informing new measures by handing over the evaluation. We reflect on the challenges, dilemmas, and successes encountered, as well as discuss the benefit of 'handing over' the evaluation process to gather scalable metrics based on economic modelling.
\end{abstract}

\section{Author Keywords}

Multi-stakeholder collaboration, scaling up, food waste recycling, behavior change.

\section{CSS Concepts}

- Human-centered computing Interaction design process and methods • Human-centered computing Field studies • Human-centered computing Contextual design

\section{INTRODUCTION}

Within HCI, there has been a recent call to address societal challenges by designing and deploying new technologies [56,59]. Topics are far-reaching: climate change; societal health and well-being; innovation in developing countries; and new forms of transportation and connectedness in urban living, to name a few. A pressing global problem is food waste management [65]. Various reports in the last few years have produced alarming data about its extent; for example, it has been estimated that, in the UK alone, 4.4 million tons of avoidable food waste is disposed of every year [50], while in

\footnotetext{
${ }^{1}$ The first author carried out this work while at UCL.

Permission to make digital or hard copies of all or part of this work for personal or classroom use is granted without fee provided that copies are not made or distributed for profit or commercial advantage and that copies bear this notice and the full citation on the first page. Copyrights for components of this work owned by others than the author(s) must be honored. Abstracting with credit is permitted. To copy otherwise, or republish, to post on servers or to redistribute to lists, requires prior specific permission and/or a fee. Request permissions from Permissions@acm.org. DIS '20, July 6-10, 2020, Eindhoven, Netherlands

(C) 2020 Copyright is held by the owner/author(s). Publication rights licensed to ACM. ACM ISBN 978-1-4503-6974-9/20/07 ..\$15.00

https://doi.org/10.1145/3357236.3395524
}

Europe household food waste is thought to account for $42 \%$ of the continent's food waste, greater than the waste levels created within the manufacturing, catering, and retail sectors. Many countries have set targets to reduce food waste by at least $50 \%$ within ten years. However, this is likely to be very challenging. Over the years, local authorities have tried various methods to improve levels of food waste recycling, but often with little impact on householder behavior.

How can researchers and designers begin to address this challenging problem? One approach is to employ a behavior change methodology whereby technologies are designed to dissuade or facilitate certain kinds of behaviors; for example, not throwing all waste into one bin. Until now, most food waste recycling behavior change projects have been smallscale, focusing on the level of the individual householder. To make a societal impact means designing at a broader level, within and beyond the individuals and communities affected. In short, it requires scaling up: working with a variety of stakeholders connected to representative communities and joining government and company initiatives to provide expertise in user engagement, user-centred design (UCD), and ethics. However, each stakeholder will have their own agendas, budgets, and methods. This raises important questions: what methods each partner will use, when and how to collaborate, and when to hand over the project from one partner to another. The goal of our research was to discover and chart how this can be accomplished.

In this paper, we present and critically discuss a 15-month food waste recycling project that was run as a multi-party initiative in London comprised of a diversity of stakeholders: government officials, strategic partners, company managers and employees. Our role as HCI researchers was to co-design an intervention with local communities that could be placed in urban housing estates to improve their food waste recycling. However, for a variety of unforeseen reasons, we were unable to engage with the residents. When faced with the unexpected situation of a hard-to-involve community, we had to change direction by adapting our design methods. This turn of events resulted in a design intervention that proved to be successful at significantly changing residents' behavior. We discuss what was involved in making these compromises and the ensuing trade-offs. We then present lessons learned in terms of the challenges we faced and how they informed our scaling up framework for addressing societal challenges. 


\section{BACKGROUND}

\section{Scaling up $\mathrm{HCl}$ research}

Scaling up is the process by which the scope of a project is considered in terms of how to make a societal impact. In general, it involves working with several stakeholders and conducting multiple studies at multiple sites over a period of time to show validity, reliability, sustainability, and in situ impact. Within HCI, this has occurred through crowdsourced studies (e.g., [27]) and designing prototypes in parallel (e.g., [2]). These efforts have shown how to design, build, and study social computing systems at different scales using crowds of remote contributors. The focus has been on how to make design more accessible by coordinating large numbers of diverse volunteers in open-ended research [67].

Others have identified various problems that can arise when scaling up research projects [11, 18, 43]. For example, Chilana, Ko, and Wobbrock [18] discuss the challenges of moving from a research project to a commercial product, noting how there are multiple stakeholders that need to be taken into account aside from users, including business customers, administrators, financers and regulators. Blumenfeld et al. [11] note, too, the unforeseen challenges they faced when trying to scale up a technology that they had developed for a school setting, including dealing with school legislation, limited resources, and organizational culture. Expectation management is also critical to a project's success [5]. For example, Balestrini et al. [7] discovered a number of mismatches between the technology intervention that they developed and what the community assumed that they were providing. Masden et al. [45] also describe how a social media app developed to support local neighbourhoods ended up raising tensions and privacy issues that resulted in it being used less than hoped for. Hence, there can be many obstacles when trying to scale up a research project.

One way of managing this difficult process is to work with stakeholders who are better equipped to support different aspects of the research, development and commercialization. However, while they may share a common goal, each may hold competing desires, influence, and values. This often means finding ways of working together to overcome such differences. Stakeholder-centered design is one such approach, whereby the needs, desires, and contributions of diverse stakeholders are accounted for with respect to the products, services, and systems in the project [29]. Consideration of everyone who is connected to or impacted by the service or system being developed also requires thinking about factors beyond user needs, including economics, transactions, policies and even politics.

An example where UX designers were involved in a multistakeholder project was in the development of a health app, where they worked alongside clinicians, medical researchers, engineers, and designers. Their role was clearly identified as experts in usability testing [22]. But it is not always clear what else one should take on. One tactic is to be upfront by articulating each party's motives when conducting design projects and research [42]. This includes taking into account the politics of co-making interventions, being mindful of the users involved, and considering the project's impact on the world at large [70]. Some argue that they should not be acting on behalf of certain groups, such as the exploited, the homeless, and those without a voice. Others err more on the philanthropic and conservation side, wanting to help save the planet, reduce poverty, and protect endangered species $[49,59]$. In these 'turns to action,' the researcher often face ethical dilemmas: for example, is the research being asked of them within the ethics code of practice required by their university, or the $\mathrm{ACM}^{2}$ ? When scaling up, these questions take greater precedence because the situation is more complicated and the impact potentially greater: with more stakeholders, there is more at stake.

There may be a need, therefore, for researchers who are working as part of large-scale projects to adopt different framings, methodologies, and ways of carrying out design and research practice [56]. As Balakrishnan et al. [4] found, integration across different disciplines and expertise can be difficult, especially when agreeing on and sharing tasks. Complexity increases with the dissimilarity between team members, culturally and organizationally. Power struggles can materialize between stakeholders, whose goals and ambitions may evolve as the project progresses. Moreover, it can appear that someone else is steering the project than was originally decided or assumed [56]. An important goal is to strive for equity and participation, where communication is seen to be transparent and accountable [36]. This requires knowing (or figuring out on the fly) how to navigate the many unknowns and uncertainties that inevitably arise and deciding what compromises to make [35]. Certain mechanisms can be adopted to tackle the difficulties that can arise; for example, Shneiderman [59] has discussed several, such as forming balanced teams with a mix of senior and junior members as well as business and academic members.

\section{Community and citizen engagement}

A central part of our research was to facilitate community engagement: the process by which researchers, practitioners, or civic entities work with a specific community on a community-driven project [58]. Such work often has a multistakeholder context, involving a small set of stakeholders supporting members of the community as leaders of the work [33]. In HCI, community engagement work has covered designing technologies for civic engagement [33], such as enabling locals to voice their opinions [25,26], area sustainability, such as reducing energy consumption or improving air quality [20,31], and support for community programs [16]. Examples where community engagement has been successfully deployed include: the design of Internet of

\footnotetext{
2 https://ethics.acm.org/2018-code-draft-1
} 
Things toolkits in developing nations [32]; apps for tracking health [20], the use of robots in hospital wards [23] and the design and deployment of digital noticeboards for remote communities in Australia [51,60]. Other projects where community members have played a central role not just in co-creating an intervention but also using it to change their own behavior includes Tidy Street, where a public street graph depicting the community's energy use over a period of time helped them significantly reduce it [10]. Most community engagement projects have been ethnographic or qualitative in nature, revealing emergent phenomena, new design practices, and lessons learned [13]. Benefits include fostering trust, generating interest from residents and organizations, and creating a better fit between people and technology [21]. But there are challenges: creating suitable conditions for research [68] and foreseeing outcomes [24].

Such projects are often democratic [41] or emerge directly from within a community [21]. But what communities want and what researchers can do may be at odds. For instance, conflicts can arise [25] when researchers propose ideas that go against the community's set of values and/or governance. In one case, a community was introduced to the idea of using pirate radio to broadcast local issues of concern (e.g., pollution levels). While some members were keen, others were not so happy, considering the idea dangerous and even reckless. In another project on visualizing street data, tensions arose between councils and residents over what data should be presented [62]. When disconnects between stakeholder groups occur, they may be overcome by generating connections through appropriate dialogue [4]. Local organizations and statutory bodies who represent and/or manage access to key communities, e.g., neighborhood associations [41], may also try to assist.

Researchers are increasingly being asked to work on projects for and potentially engage with communities. They are also required to work with stakeholders who may or may not be members of those communities but who are responsible for their operation and well-being within the larger cityscape. In contrast with community engagement that is citizen-led, these kinds of projects are typically directed by governments, councils, and public organizations who seek ways of encouraging citizens to engage with civic issues, assess policies, and contribute to public projects. The role of user researchers in such projects has tended to be pragmatic: for example, how to enable citizens to provide input for the topic in question and, where possible, contribute to emergent concepts and designs [cf. 57]. This typically involves visiting local sites, talking to people, and inviting them to workshops.

Another challenge facing community engagement is gaining access to citizen groups [72]. This often requires considerable effort: recruiting collaborators, encouraging participation, and developing relationships as outsiders [34]. When they do come on board, a subsequent challenge is how

\footnotetext{
${ }^{3}$ https://www.fixmystreet.com
}

much of a voice to give citizens within the design space. One example wherein much leeway was given was the mobile app FixMyStreet ${ }^{3}$, where residents were encouraged to share their opinions with developers. Another digital tool designed to encourage community discourse is a virtual agent that community members can talk to [1].

A further concern is how a proposed intervention will be approached, used, or ignored in the intended context. Research in the wild $[21,53,56]$ provides an alternative approach for researching this, where an app, service, or product being developed for a community or user group is researched, designed, and tested in the setting it is intended for before being deployed. Those conducting research in the wild often work with communities [7] by deploying technology probes developed by research teams to provoke people to act, react, or reflect in various ways, in situ.

\section{Designing behavior change interventions at scale}

Advances in technology are enabling councils, companies, and communities to envision how to make cities 'smarter' by instrumenting them with adaptive, interactive, and social technologies, such as IoT, that can generate new and big data about citizens and environments [15,73]. Opportunities are appearing for rethinking how to design behavioral change interventions to work at scale, engage a sector of the public, and have a significant impact. Much has been written about which methods are effective, such as nudging and social norms (e.g., [28]), what theories can be applied (e.g., [64]), and which interventions have been designed and tested (e.g., $[3,9,30,55])$. A common approach is to develop educational materials; for example, placing posters in public areas, sending out fliers to residents, and creating public websites, e.g., Recycle Across America's digital campaign with celebrities $^{4}$. Uptake of this approach is widespread; it is quick, scalable, and relatively cheap. But it has only had modest success that tends not to be sustained once the local borough's interest and funding runs out (see [7]). Technology interventions, using ambient devices and displays, have also shown much promise. An early example is a sculpture placed next to a user's computer that slumped over if the user sat for a long time without taking a break [38]. Ambient displays that lure people to take the stairs instead of an elevator in a workplace [55] have been found to elicit much intrigue and discussion over a period of time. Moreover, even though few people admitted to changing their behavior, logged data of their actual movements showed a significant increase in stair usage.

Applying the design principle of playfulness has also been effective at attracting and sustaining interest from a diversity of people $[40,54]$. Play can tap into people's curiosity and generate spontaneous experiences that are low investment but grounded in the activity $[37,54,66]$. The 'fun factor' has also been found to foster motivation, enjoyment, and social interactions $[12,40]$. Public installations targeted at recycling

${ }^{4}$ http://www.recycleacrossamerica.org/psa-campaign 
behaviors have used playful feedback to provoke surprise and reflection. For example, the World's Deepest Bin [69] played a sound emulating an item falling a great distance when something was thrown into it. Other examples include the Bottle Bank arcade machine [69], which rewarded users when they recycled a bottle, and BinCam, which took a photo of what was thrown in a kitchen bin and uploaded it onto Facebook for commentary [19]. A challenge when designing such interventions, however, is how much playfulness to add and what form should it take [46]. This is especially pertinent when scaling up: is it possible to design a playful prototype that the various stakeholders find acceptable?

The remit of our project was to design an innovative intervention that could improve a community's food recycling behavior, one that could be scaled up for use citywide. We present below the design processes, the challenges and how these were resolved, and what was finally achieved.

\section{THE FOOD WASTE RECYCLING PROJECT}

The 15-month project was a multi-party initiative managed by a waste company in collaboration with various London boroughs. The goal was to develop a food waste recycling program at scale and provide evidence for its effectiveness so that that all boroughs could justify implementing it. During the planning phase of the project, we agreed to develop an innovative behavior change technology that could help people habitually recycle food waste by separating it from other kinds of waste. The setting was multi-tenancy flats on housing estates, which feature a high density of inhabitants who share communal recycling bins.

The roles of and relationships among the stakeholders ${ }^{5}$ are shown in Figure 1. These included representatives from the mayor's office, the service provider, an urban innovation organization, ourselves, and three local boroughs. The citizens (i.e., the householders in the flats) were viewed as being at the centre of the project. Much pre-planning occurred over a 6-month period to make explicit and agree on the roles and time periods for the work packages. As the university research partner, we were responsible for the citizen engagement and design intervention phases.

The boroughs were keen to work with a housing estate where recycling levels were poor and community engagement low. Our initial plan was to follow a user-centred approach: involving requirements gathering, design iterations, and deployment in a real-world setting to collect data on actual behavior. For this, we proposed stakeholder interviews, codesign workshops, in-home interviews with residents, and observations at the site.

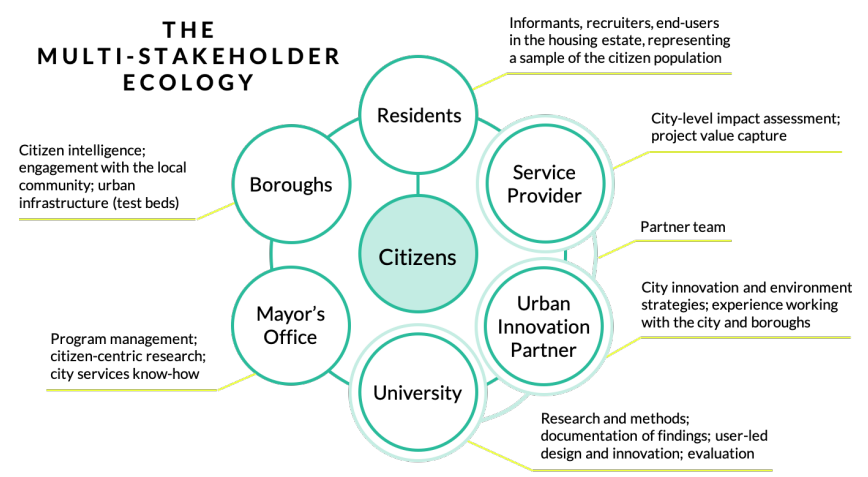

Figure 1. The roles and responsibilities of the stakeholders.

It was agreed that our findings from the citizen research would allow the urban innovation partner to derive metrics for predicting the increase in food recycling and concomitant energy that could be saved in a year-long period. Their plan was to conduct a formal impact assessment that could be fed into an economic forecasting tool. They proposed using a customized methodology with impact indices that could be compared against government economic and social impact targets. The waste management company considered this to be a critical form of ecological validation: providing objective evidence for the effectiveness of the design intervention to change householders' recycling behavior.

It was also agreed that the urban innovation partner would collaborate with us on early design activities. We planned codesign workshops with citizen groups to progress our designs that would take into account their views, opinions, values, and circumstances. Representatives from the local boroughs also said they would help us recruit local citizens.

But despite our forward planning, including how to collaborate and when to hand over, progress was only made through comprising and seizing new opportunities. Indeed, we quickly realized that conducting a large-scale, multistakeholder design project is not straightforward: we had to confront unforeseen problems, change tack, and abandon planned methods. Designing at scale involves managing this process as much as it does collecting user feedback and ideas. Here, we account for how we managed and embraced the unexpected through a process of adaptability and reflexivity.

\section{METHODOLOGY}

Reflexivity (cf., [39,52]) involves accounting for one's actions, decisions, thoughts, and worries when engaging in field work [39,52]. Johnson et al. [39] discuss how being aware of one's role as a researcher can sensitize one to salient aspects of people's experiences, particularly for hands-on interventions that can disrupt everyday routines. The effect of conducting research on the researchers themselves - the

\footnotetext{
${ }^{5}$ While we too qualify, for simplicity we use 'stakeholder' to refer to the other stakeholders in general, and 'partner' to specifically refer to members of the partner team.
} 
dilemmas and anxieties they face, and how they deal with them - is also an important source of knowledge [14].

The process of being critical and transparent about our experiences as a partner on a multi-stakeholder project of this size and ambition enables us to be more accountable [47]. It can provide other researchers with insights about what they will have to contend with when attempting to scale up their research within the complexity of our 'messy' world. To this end, we wrote notes, kept diaries as per [48], and recorded meeting minutes. We also conducted interviews within the partner team and engaged in critical discussions of our conclusions with each other while writing this paper.

\section{SCALING UP AND BEYOND: THE CHALLENGES}

A recurring theme throughout the project was managing uncertainty: how to recognize and resolve unexpected issues while trying to follow our methodology. At the same time, we learned how to capitalize on the unforeseen opportunities that arose. Below we present the most salient and representative examples as a set of ten challenges.

Challenge 1: Managing different management structures As researchers, we were used to a flat management structure. But as part of a multi-stakeholder team, we had to fit in with a different style of management to which the service providers were accustomed. They proposed a more formal and structured process, including a management team and a senior sponsor board. We were asked to attend several predefined management meetings, as well as write up and present formal documents with action points, milestones, work plans, and anticipated deliverables. This explication process is something we, as academic researchers, do not normally engage in. However, despite our early resistance, we were pleasantly surprised at how working in this way enabled us to disseminate and legitimize our research. In particular, it gave us an opportunity to convince the partners unfamiliar with our approach of its the value and novelty.

\section{Challenge 2: Reconciling differences in choice of site}

The initial site proposed by the borough stakeholders was based on their perceived suitability for engagement, current food waste recycling performance, and previous experience with the council. While the last two factors were clearly defined, the first was open to interpretation. Following HCI research guidance [6], we recommended choosing a site where there were committed recycling champions: people already motivated to help get other residents on board, act as mediators, and keep the project momentum going. But the borough stakeholders proposed that tackling recycling behavior in a way that would be effective at-scale should begin with a housing estate that had been resistant to change. While challenging, success would lead to new insights for helping other housing estates with low rates of recycling. As a compromise, we agreed to take on this challenge by initially trying to understand the reasons behind this resistance, assuming we could then find a champion.
Challenge 3: Reconciling different interview practices

Our plan was to conduct on-site interviews with residents. A member of the service provider team also teamed up with us. However, we soon discovered we had different approaches. Our interview protocol used carefully phrased questions to avoid unduly influencing responses and keep the focus on the project. In contrast, their approach was more informal and personal, sometimes offering their opinions and making suggestions to the interviewees. Their rationale was that this kind of conversational style enables rapport and trust to be built. We needed to consider whether a compromise could be made. We asked ourselves whether it mattered if our more structured protocol became a more open-ended one that, while not consistent across participants, could built rapport between ourselves and the residents but also with each other. In the end, we accepted their reasoning: that trying to build trust with the residents - and between us-was more important than following a structured interviewing approach.

\section{Challenge 4: Engaging with resident stakeholders}

Although the council had worked with the housing estate before, it proved difficult for them to find willing residents or a first point of contact. Those we spoke with were wary of us, seeing us as strangers, and chose not to accept our invitation to be interviewed. We also discovered that some residents did not think too highly of the council, who they felt did not deal with their complaints or concerns. We then adopted a different tack to engage residents. We tried wordof-mouth networking through the service provider's network and the residents board. But again, we came up against resident resistance. One board member informed us that the residents had greater problems to deal with than waste recycling. Next, we tried cold calling, doorstepping, leaving fliers, and sticking up posters on-site. We also attended events organized by the residents' association, such as a weekly tea session, but only the organizers showed up. We also set up a stall at the housing estate's summer festival. While these alternative approaches resulted in some residents appearing keen at first, and us being able to collect a few contacts, none responded on follow-up.

At this point (approx. 7 months in) we decided to try an unconventional and indirect method: making observations of the insides of the communal bins. We took weekly photos and compiled these into an aggregate visualization matrix (Figure 2) for our partner team. This visual evidence revealed how almost all bins were contaminated. By this is meant other non-food materials present in the bin, such as pizza boxes. It also highlighted a mismatch in our understanding of what constituted contamination: while the stickers on the bins stated 'no plastic bags,' much debate in our team ensued as to whether plastic bags qualified as contamination - as some are biodegradable. These observations were thus able to reveal insights about the residents' current waste disposal habits indirectly, and also the need for clarity within the partner team and council about best practices and what materials to provide to the residents. 


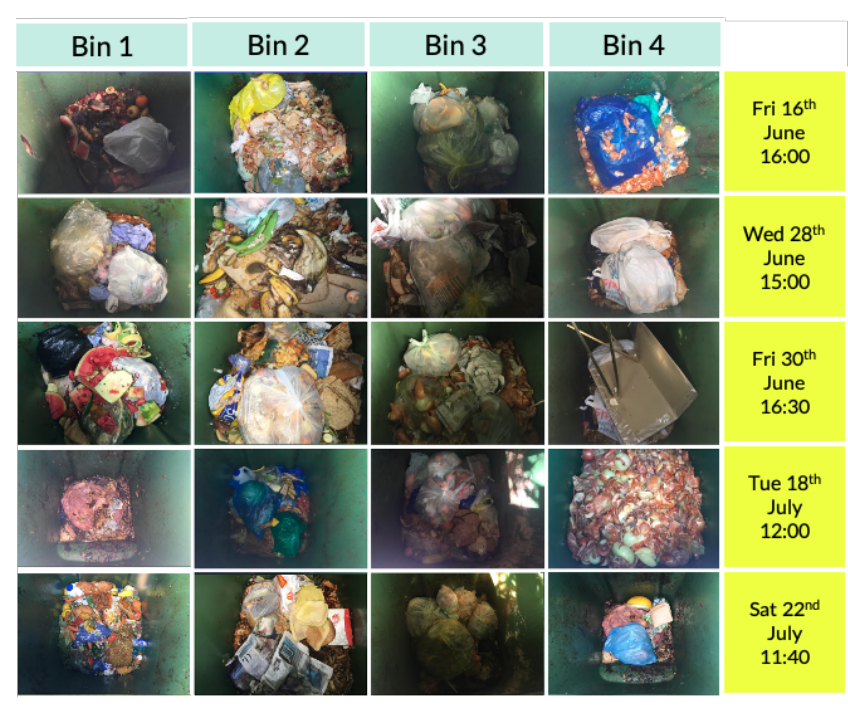

Figure 2. Example of an aggregate visualization matrix of the contents of the communal bins on the housing estate.

We also went on an impromptu walkabout with the partners at the housing estate. All were able to experience the state of the food waste bins firsthand: smelly and covered in flies, with the metal handle too hot to touch (in summer). A resident also came out to tell us how the food waste bins were attracting foxes. In doing so, it allowed us to notice how inconvenient it was for some residents to walk from their flat to the communal bins.

Based on these observations, we proposed three core user requirements: that the food waste recycling activity be made (i) more hygienic, (ii) more convenient, and (iii) include an awareness-raising solution. The other stakeholders, having experienced these factors themselves, agreed. Hence, changing our methods was not only necessary but also serendipitously beneficial.

\section{Challenge 5: Resolving which form of compensation}

When it came to compensation, we assumed it would be our responsibility, but instead it became a team one, involving collective decision-making: not just the 'what' but also the 'how' of resolving the issue. As part of this decision-making, it was agreed that the service providers would pay the participants. But then they discovered that they could not handle this form of monetary compensation as it could be viewed as offering financial rewards to their customers, going against their regulations. They instead suggested providing merchandise with the company's branding on it. But we felt that this kind of compensation would contravene our university ethics approval. The service provider then suggested a gift from a retail company: an orchid and a reusable vase which we agreed upon to prevent further delays to the project, rationalizing that providing an orchid would be eco-friendly, low-impact, and reflect the values of the project. We then had to decide when to give it: after participating in part or all of the study? While money can be split, a plant cannot.

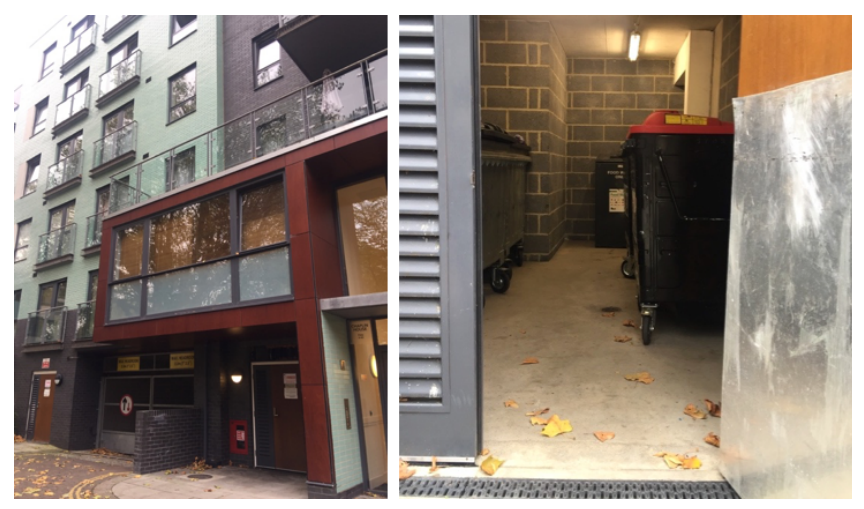

Figure 3. (a) The second housing estate and (b) its bin storage.

Then, during a meeting with the head of the residential board, a council member discussed how cash and vouchers were also their usual form of compensation and that they would normally provide twice as much as what we had proposed. By another stakeholder articulating their practice, the service provider was given new evidence to persuade their company that we should be offering the participants monetary vouchers. This was what was finally agreed on. Hence, what we expected to be a straightforward decision turned out to be complex. The protracted process over a small aspect of the project revealed a friction between corporate and university cultures that took much effort to resolve.

\section{Challenge 6: Letting go and trying again}

After being unable to engage with the residents directly, we had several discussions with the partners about how we should proceed next. The borough was very keen to continue: we had invested a lot of time and energy, and it would look bad to 'give up' at that point. We pointed out that residents should be involved in the process rather than subjected to an intervention without consultation. The dilemma we faced was how to proceed without citizen engagement of the level envisioned. We agonized over whether it would be okay to move into the design phase based largely on our indirect observations of the site. Also, would we be doomed if we placed our design intervention at the same site where we had encountered so much disinterest?

We all agreed that we had to start the design phase and would try to invite residents to join us during the co-design sessions. The partners also accepted that we should find another housing estate where there was at least one resident who could champion the project. If successful, we could return to the original housing estate and test our intervention.

After several weeks, the council found a similar housing estate in the same borough that was not performing well in terms of food waste recycling. This site (see Figure 3a) consisted of 40 newly developed, midrise, multi-tenancy flats. It had an amenable setting for the communal bins: an indoor room that was only available to residents, caretakers, and council members (see Figure 3b). Passers-by could not fly-tip and the bins would be safe from environmental issues and security risk (a locked, contained room). 
Challenge 7: Compromising design innovation with the practicalities of scaling up a prototype

The next phase of the project involved co-designing ideas to overcome the various barriers to food waste recycling we had gleaned from the first phase: lack of convenience, lack of awareness, and poor hygiene. However, our plan to run the co-design workshops with residents backfired, as again none were willing to take part. Instead, the designers in our team created a set of sketches/storyboards and a user journey based on our observations of the original estate (Figure 4). Representatives from other stakeholder groups participated in the workshop. Each contributed design ideas-simple sketches of possible interventions or parts of interventions. We then chose a final idea after all the workshop participants ranked the different designs using a set of predefined criteria: whether the idea was playful, informational, rewarding, or functional. This was to enable a systematic way of comparing and judging the qualities of the designs, rather than allowing individuals to focus only on their own concerns of feasibility, cost, etc.

The most highly rated ideas were a bin monster that called out to people in the vicinity (low-tech), a voting bin with two containers acting as tallies for a weekly question (mid-tech), and a food waste visualization showing energy inputs and outputs (high-tech). The most preferred design was the lowtech bin monster: the most playful, engaging, and scalable in terms of cost, maintenance and mass production. From a novelty perspective, we preferred the relatively high-tech IoT idea of providing a food waste visualization to different groups of residents showing their relative food waste recycling efforts in terms of weekly amounts of energy saved, as it fitted in with our ongoing research in this area. However, the council members noted that this design would be too expensive and required too much tech to make it work, and hence would not work at scale or be sustainable.

It was a humbling experience for us to have our preferred design concept rejected: the quandary for us was that the low-tech bin monster idea was not novel and thus, we worried, would not be seen as making a new contribution to HCI knowledge by our peers. This tension resulted in us experiencing a kind of cognitive dissonance.

As a compromise, we agreed to bring the bin monster to life using a mix of playfulness and anthropomorphism realized through a small amount of relatively cheap electronics (Figure 5). The other stakeholders stressed the importance of making its appearance not too scary and not too cute: the goal was to enable all residents to be attracted to it and want to keep 'feeding' it their food waste. Moreover, the electronics and other materials had to be cheap for scalability.

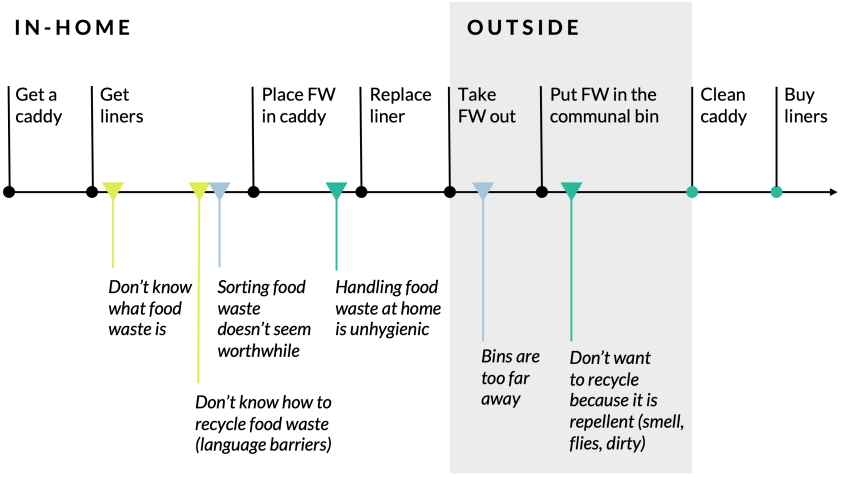

Figure 4. User workflow showing breakdowns (beneath the line) and solution points (above the line) when moving from inhome to outside during a typical recycling cycle.

We designed the bin's eyes to light up when approached, followed by 'cooing' to entice residents towards it. If the bin lid (or 'mouth') was then opened, its eyes became sparkly and it would make a sound of anticipation. If something (i.e., food waste) was placed inside, it expressed approval by making a 'munching' sound in a contented way. While the idea of feeding a creature that mimics a response using eating sounds and eye animations is not new (e.g., [55] and TheFunTheory. $\operatorname{com}^{6}$ ), our goal was to see how it would change resident behavior in situ over time.

We also specified how to sustain behavior change for the whole process of recycling food waste, from the kitchen to the communal bin. This required providing other free materials to each flat, including a small caddy for the residents to use in their kitchens, a set of biodegradable bin liners, and an information sheet made up of stickers as reminders about what food waste is and is not.

Challenge 8: Handing over responsibility when not there We were unable to install the Bin Pal ourselves owing to a mix-up by the transport company who were delivering it. Instead, the service provider manager agreed to install the bin. This was achieved through a researcher verbally explaining over the phone how to set up the electronics to make the facial features and logging work. They succeeded in getting the bin working.

An unexpected benefit from this impromptu collaboration was that the partner experienced the thrill of hands-on research in the wild. She was very proud, taking photos of the functioning Bin Pal and sharing them with her company. She then took on the responsibility of maintaining the Bin Pal (that she nicknamed 'the baby') as a 'technology steward' [71]. Handing over the setup and upkeep of the Bin Pal to another partner turned out to be a positive experience, allowing her to learn new skills and feel accomplished.

${ }^{6}$ http://www.thefuntheory.com/ 


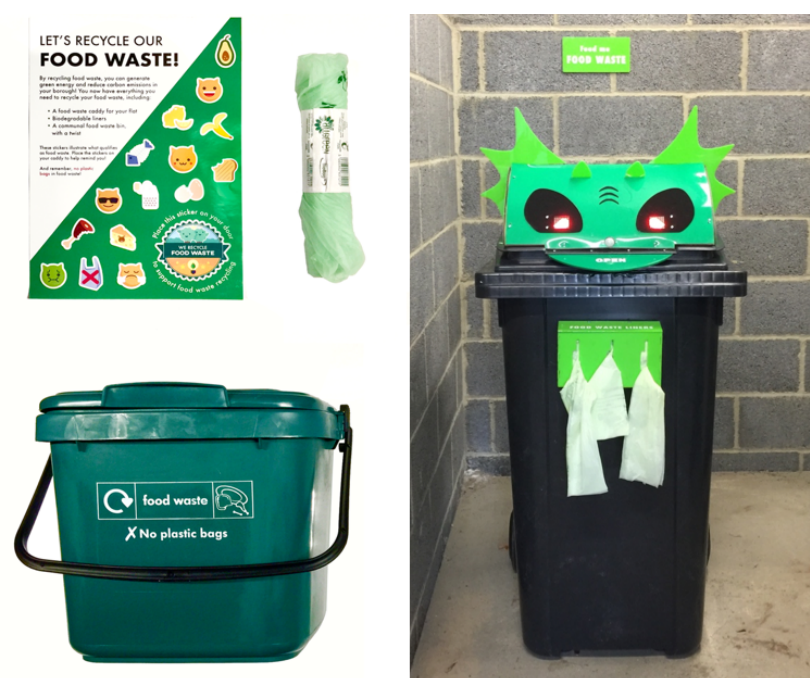

Figure 5. The Bin Pal (right) with the home starter kit (left). Sticker sheet icons by Freepik (Flaticon Basic License).

Challenge 9: Handing over the evaluation of the project Part of the innovation consultancy's role was identifying appropriate evaluation metrics by establishing a baseline and setting up a counterfactual (i.e., what would happen if the intervention never occurred) based on the site data. We were not involved in this process; they ran the evaluation study at the housing estate collecting data over a period of 3 months. To do this, they commissioned a contractor to measure and record the weekly weight of food waste. Unlike in research projects where the researchers collect and analyze the data themselves, we had to wait for our partners to let us know at the end of the study whether the intervention was successful and to what extent. Having been deeply engaged in the project for so long, it felt strange to no longer be involved. But the upshot was that the evaluation was more objective: the evidence and outcome of which we could not influence.

The main metrics were: (i) the weekly weight data and (ii) the waste disposal cost data provided by the council. The latter was determined by comparing the weight of waste sent to the landfill and the weight of acceptable food waste (i.e., not contaminated), quantified at the food sorting site. As the project was already six months late, it was agreed that they would only be able to collect data for a 12 -week period, following a 3-week period before the intervention was installed to provide a baseline. The weight of collected food waste was also recorded at two other sites as a way of determining by comparison whether any changes were due to the intervention. The team considered this to be a sufficient means of providing data and evidence for the economic forecasting stage, to allow them to decide whether the project could be scaled up to other boroughs.

The data showed an upward trend in food waste recycling from weeks 2 to 12 and a downwards trend from weeks 13 to 16 , reflecting the extent of a novelty effect. During this latter period, there were also problems with replacing the battery of the Bin Pal, which could also explain the lower data levels. Overall there was a significant improvement in food waste collection: $281 \%$. for the period. Using the UK government's 'The Green Book' for sustainability estimates, the revenue from the electricity generated from the food waste was calculated to be $£ 27,677$. We were all surprised, and the council and service provider stakeholders were impressed by these figures. In the report, it was noted: 'If we apply the same food waste collection level observed in the pilot (121 kg/flat) ... a £94/ton saving when food waste is diverted to $A D$ facilities [for generating electricity] ... we estimate [...] approximately £1 billion in savings ...' The outcome was potentially massive and provided evidence that the new intervention could be effective at scale. This was music to our ears since we could not have made such a prediction based solely on our study findings.

\section{Challenge 10: Accessing resident reactions}

While deploying the BinPal in the housing estate a few of the residents became curious about the project. This enabled some rapport and trust to be built between us. The residents we came across were largely positive, for example: 'It's fun! It is easy to use the bin and it looks nice, it's easier to us because it is not as tall as the previous one.' Another said, 'The bin is visible and colorful, it looks nice and clean.' The manager of the housing association also mentioned that there was an absence of feedback - a positive meaning since the residents tended to only report negative feedback to them. The insides of the bins were also photographed once a week over a period of 4 weeks; this time, they showed very little contamination. During one visit, we noticed that one of the Bin Pal's ears had been broken and carefully reattached: someone had taken it upon themselves to fix it (Figure 6). This act of repair suggests that residents were taking responsibility and perhaps 'caring' for the Bin Pal.
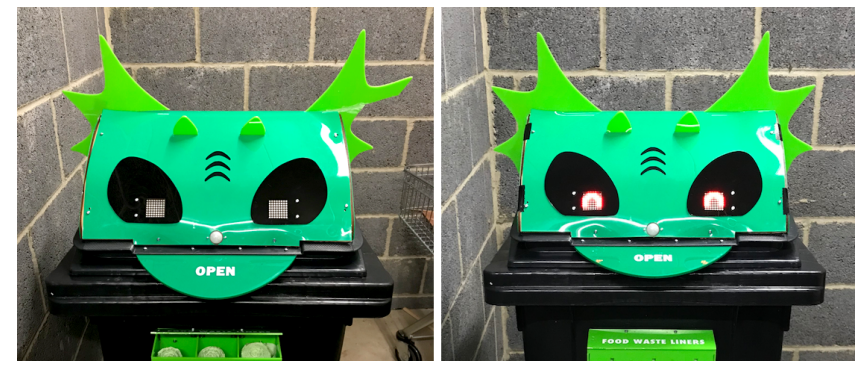

Figure 6. The Bin Pal's broken ear (left) later fixed (right).

\section{DISCUSSION}

Our project demonstrates one way of scaling up for the societal challenge of food waste recycling. This form of scaling up was not conventional, i.e., engaging hundreds of participants at multiple sites. Rather, it involved working as part of a multiple stakeholder team where the users could not be directly engaged.

A novel part of the scaling up in our project was handing over the evaluation to another stakeholder who assessed and predicted how our design intervention could make an impact on society. Their approach was to use the data collected from 
the in situ intervention and analysis of food waste weight metrics as input for economic modelling at different scales (e.g., making predictions for a whole year). This type of prediction is the currency of councils, who are in the business of making decisions when investing in technology at-scale for a borough or a city. Instead of trying to mass produce the Bin Pal to run a large-scale study, the data from three settings was used to provide the evidence. Similar to how economists make predictions about savings, costs, etc., based on models and simulated data, our project has shown that it is possible to 'multiply' the data from a relatively small user study to make large-scale predictions about impact. The service provider and urban innovation partners can use this assessment to inform local councils using the lingo to which they are accustomed of the potential benefits of Bin Pal for increasing food waste recycling at a larger scale.

From a behavior change perspective, we can also consider the reasons for the improvement in recycling and reduction in contamination levels. One of the main factors appears to have been the Bin Pal's engaging and playful feedback, transforming an unpleasant task into a fun one. Furthermore, designing for all aspects of the recycling task, from separating and storing the waste indoors to depositing it outdoors in a communal bin, appeared to play an important role. Having a critical mass of residents at the second site participate also was important. Moreover, that the change in recycling level was significant and sustained over three months suggests that the Bin Pal's success did not rest on a novelty effect but also led to residents developing a new habit of recycling their food waste, that was sustainable.

In line with other research involving multiple stakeholders from non-HCI educational projects $[11,43]$, we were able to show how a diverse team can work together to achieve success, even with different agendas, constraints, and methods of working. However, a major downside is having to compromise on various aspects of the design process itself. Indeed, a persistent dilemma for us was the many changes and compromises that had to be made in order to move the project forward, especially related to pushing forward our research agenda. As others working in a different context (i.e., the world of start-ups and venture capital) have discovered [18], the process of pursuing the goal of scaling up can result in having to scale down aspirations. Thus, our experience was a two-sided coin: on the one side, an opportunity to address a societal problem at a bigger scale than possible on our own, but on the other, a challenge for us to follow a citizen engagement process while being able to make a contribution to HCI knowledge.

Not being able to find a way of meaningfully engaging with residents at the first housing estate, despite our numerous efforts, left us frustrated and questioning the 'user-centred' and 'resident engagement' principles we had agreed to incorporate in our methodology. As an alternative, we had to adopt and adapt to more indirect methods of observation and 'proxy' designs: ones that were focused on our perceptions of the residents' needs, their environment, and the daily barriers they faced. This raises the question of whether what we conducted can be viewed as citizen engagement, or more generally, user-centred design. It certainly was not participatory design or design research. Instead, we would argue that having to change our methods so as to progress the project can be viewed more from the perspective of 'sensitive' HCI [70], where the use of indirect means results in empathy and a better understanding of why there was a very low rate of recycling. It also led to insights about supporting different aspects of recycling, including other forms of support, such as awareness of what recyclable food waste is and a route that started in the home.

More generally, this raises the question of what designers and researchers can do when they have limited access to users: when people are resistant, suspicious, not interested, or too busy to participate in a community-based or city-wide project. We cannot assume that we can 'win' local people over at the start and participate throughout, even if what is being created is intended to benefit them. Instead, we argue that, in such circumstances, inviting them to come on board when there is a prototype that can be given to them to test out and use (i.e., in the wild research) can be beneficial.

\section{A framework for scaling up}

Instead of discussing our findings in terms of how they support or extend a given design methodology, we propose it is more valuable to situate our work within a general framework on how to 'scale up' [56]. Our proposed framework is comprised of three interrelated aspects: (i) the people, in terms of their roles and relationships; (ii) the method, in terms of how to adapt user-centred methods when working within a multi-stakeholder context; and (iii) the impact of 'multiplying' and projecting the results of a small scale study at one site to a city model.

\section{Scaling up the people}

A multi-stakeholder context typically involves entrance to not just one 'community' - residents and the gatekeepers and authorities associated with the community-but entrances to multiple communities and their associated ecologies (e.g., their collaborators, regulatory bodies, and managers in industry, local authorities). Figure 1 shows a simplified diagram of our network of stakeholders. In reality, the ecology included many more nodes: stakeholders who had smaller roles and impacts, or who were involved in the project at certain stages or for certain lengths of time, or even joined and left and joined again as the project unfolded. Unearthing and cultivating relationships between ourselves and other entities (we do for ourselves), as mediators of other entities (we do for others), and as mediated entities ourselves (others do for us) is paramount. Managing this requires 'scaling up' our role, similar to the Manzini's notion of the human-centered 'urban planner' [44]: a combination of multi-stakeholder (rather than multi-site) manager and planner, who discovers the needs of the disparate parties involved and attempts to balance them, while cultivating (in 
the sense of improving) a shared agenda and understanding towards accomplishing the overall goals of the project.

A difficulty, however, is learning how to navigate the existing social and political structures that each stakeholder works within. Extra work is required not only for the work to happen within organizations [36], but also to tackle flare ups across organizations that have different management structures. This also involves adapting roles and methods to fit with unfolding events, where the researcher gains knowledge in parallel with their relationship with those involved in knowledge production $[8,41]$. Our prior planning was best viewed as a starting point: a resource that allowed us to accommodate the way the others worked. Suchman's [61] illustrative example of such situated action being akin to canoeists riding the rapids is apt. Despite a great deal of deliberation and the formation of precise plans, being able to navigate the rapids depends on each person's skills and ability to react to whatever rapids come their way.

Having a social protocol for dealing with unexpected events and misunderstandings is key. We view this as a form of entanglement [41:1351] between the various stakeholders, where changes, compromises, and a cultivation of shared interests, goals, and values are the driving force. This involves acting as a kind of synchronizer towards achieving the overall goals of a project. The researcher can explore new ways of mapping out these roles and relationships and '(re)designing' the design/research process accordingly. This is fundamentally an exercise in empathy: stepping into other stakeholders' shoes by actively imagining how the situation is for them and the reasons behind their decisions, opinions, and views [44]. In doing so, we can broaden our perspective beyond ourselves and the users.

\section{Scaling up the method}

Scaling up the method means knowing how to compromise the methodology within the multi-stakeholder team. It also means assessing how such compromises will affect the integrity of the design. This becomes a process of moving into uncharted territory, similar to [18]: managing hold-ups and unforeseen problems while considering the restrictions on the time allocated to different steps in the process. Seemingly trivial logistical tasks, such as participant compensation, can end up being protracted as a result of unexpected cultural differences. Furthermore, even when a method is agreed upon, the way it is perceived and conducted by each stakeholder can be different. To overcome such challenges, open discussion with the other stakeholders and personal flexibility are essential. Being willing to let go of one's prescribed ways of being and doing enables the researcher to accommodate unexpected demands and manage setbacks. The researcher, however, must also put in substantial effort to coordinate successful interdependence [4]. Indeed, not being in control and handing over ownership at key times can be a salutary lesson [63]. In doing so, new and potentially better ways of evaluating design can arise.
Scaling up for impact

There is a growing concern that research involving some kind of high-level technology intervention should be able to demonstrate how it will make a societal impact, such as to reduce the carbon footprint, energy consumption, and so on. We showed how it is possible to envision this by combining a variety of methods from different stakeholders. This involved moving from 'local solutions to local problems' [35] into a 'local impact for societal problems' space. We also showed how others in government and industry, with different expertise and skills, can evaluate our design prototype and, in so doing, obtain a set of impact metrics with which the government and business worlds are more familiar. Handing over the research baton in this manner was beneficial, productive, and rigorous in our project, resulting in an independent way of measuring impact at scale. As our project has shown, scaled up measures, such as economic forecasting grounded in governmental metrics, can be used in conjunction with user-centered methods to generate a more objective view of what might happen if the intervention was scaled up. The ability to make this kind of economic impact prediction is something that is normally beyond what designers and researchers can achieve alone. Being able to predict a societal perspective of savings (in this case, £1 billion per year) is very powerful. Moreover, such an approach to evaluation can reduce the risk of confirmation bias [17], the unconscious framing of the research question to match the study findings and the selection of statistical tests and/or qualitative data to support the desired result.

\section{CONCLUSION}

Our project illustrates how to address a societal challenge in a scaled-up way by collaborating with multiple stakeholders. We have reflected on how we achieved this through the case of attempting to improve food waste recycling rates by way of a low-tech, playful intervention. But there were many challenges: we had to compromise and adapt to unexpected twists and turns. Based on our experiences, we created a framework on how to scale up through the merging of disparate people, methods, and minds. A benefit of working with others in this unpredictable way is to discover new means of making and measuring a larger impact on society.

\section{ACKNOWLEDGEMENTS}

This research was partially funded by the ICRI Sustainable Connected Cities Institute and Ferrovial Services. We thank all our partners on the food waste recycling project for their contributions, especially Raluca Ciungu and Mark Saunders. We thank Can Liu, Frederik Brudy, and Ben Bengler for their technical and prototyping support, as well as Licia Capra and the ICRI members of the UCLIC lab for ongoing feedback. Thanks also to Ben Shneiderman and the other reviewers for their comments on an earlier draft of this paper.

\section{REFERENCES}

[1] Shubham Atreja, Pooja Aggarwal, Prateeti Mohapatra, Amol Dumrewal, Anwesh Basu, and Gargi B.

Dasgupta. 2018. Citicafe: An interactive interface for citizen engagement. In 23rd International Conference 
on Intelligent User Interfaces (IUI '18), 617-628. https://doi.org/10.1145/3172944.3172955

[2] Eytan Bakshy, Dean Eckles, and Michael S. Bernstein. 2014. Designing and deploying online field experiments. In Proceedings of the 23rd international conference on World wide web (WWW '14), 283-292. https://doi.org/10.1145/2566486.2567967

[3] Madeline Balaam, Stefan Rennick Egglestone, Geraldine Fitzpatrick, Tom Rodden, Ann-Marie Hughes, Anna Wilkinson, Thomas Nind, Lesley Axelrod, Eric Harris, Ian Ricketts, Susan Mawson, and Jane Burridge. 2011. Motivating mobility: Designing for lived motivation in stroke rehabilitation. In Proceedings of the SIGCHI Conference on Human Factors in Computing Systems (CHI '11), 3073-3082. https://doi.org/10.1145/1978942.1979397

[4] Aruna D. Balakrishnan, Sara Kiesler, Jonathon N. Cummings, and Reza Zadeh. 2011. Research team integration: What it is and why it matters. In Proceedings of the ACM 2011 conference on Computer supported cooperative work (CSCW '11), 523-532. https://doi.org/10.1145/1958824.1958905

[5] Mara Balestrini, Jon Bird, Paul Marshall, Alberto Zaro, and Yvonne Rogers. 2014. Understanding sustained community engagement: a case study in heritage preservation in rural Argentina. In Proceedings of the 32nd annual ACM conference on Human factors in computing systems (CHI '14), 26752684. https://doi.org/10.1145/2556288.2557323

[6] Mara Balestrini, Yvonne Rogers, Carolyn Hassan, Javi Creus, Martha King, and Paul Marshall. 2017. A city in common: A framework to orchestrate large-scale citizen engagement around urban issues. In Proceedings of the 2017 CHI Conference on Human Factors in Computing Systems (CHI 2017), 22822294. https://doi.org/10.1145/3025453.3025915

[7] Mara Balestrini, Yvonne Rogers, and Paul Marshall. 2015. Civically engaged HCI: Tensions between novelty and social impact. In Proceedings of the 2015 British HCI Conference (British HCI '15), 35-36. https://doi.org/10.1145/2783446.2783590

[8] Shaowen Bardzell and Jeffrey Bardzell. 2011. Towards a feminist HCI methodology: Social science, feminism, and HCI. In Proceedings of the SIGCHI Conference on Human Factors in Computing Systems (CHI '11), 675-684. https://doi.org/10.1145/1978942.1979041

[9] Shlomo Berkovsky, Mac Coombe, Jill Freyne, Dipak Bhandari, and Nilufar Baghaei. 2010. Physical activity motivating games: Virtual rewards for real activity. In Proceedings of the SIGCHI Conference on Human Factors in Computing Systems (CHI '10), 243-252. https://doi.org/10.1145/1753326.1753362

[10] Jon Bird and Yvonne Rogers. 2010. The pulse of tidy street: Measuring and publicly displaying domestic electricity consumption. In Proceedings of the Eighth
International Conference on Pervasive Computing (Pervasive 2010), 1-6.

[11] Phyllis Blumenfeld, Barry J. Fishman, Joseph Krajcik, Ronald W. Marx, and Elliot Soloway. 2000. Creating usable innovations in systemic reform: Scaling up technology-embedded project-based science in urban schools. Educational Psychologist 35, 3, 149-164. https://doi.org/10.1207/S15326985EP3503_2

[12] Mark Blythe and Andrew Monk. 2018. Funology 2: From Usability to Enjoyment. Springer.

[13] John Bowers. 1994. The work to make a network work: studying CSCW in action. In Proceedings of the 1994 ACM conference on Computer supported cooperative work, 287-298.

[14] Michael Burawoy. 1998. The extended case method. Sociological Theory 16, 1, 4-33. https://doi.org/10.1111/0735-2751.00040

[15] Andrea Caragliu, Chiara Del Bo, and Peter Nijkamp. 2011. Smart cities in Europe. Journal of Urban Technology 18, 2, 65-82. https://doi.org/10.1080/10630732.2011.601117

[16] John M. Carroll and Mary Beth Rosson. 2007. Participatory design in community informatics. Design studies 28, 3, 243-261.

[17] Chris Chambers. 2017. The Seven Deadly Sins of Psychology: A Manifesto for Reforming the Culture of Scientific Practice. Princeton University.

[18] Parmit K. Chilana, Andrew J. Ko, and Jacob Wobbrock. 2015. From user-centered to adoptioncentered design: A case study of an HCI research innovation becoming a product. In Proceedings of the 33rd Annual ACM Conference on Human Factors in Computing Systems (CHI '15), 1749-1758. https://doi.org/10.1145/2702123.2702412

[19] Rob Comber and Anja Thieme. 2013. Designing beyond habit: Opening space for improved recycling and food waste behaviors through processes of persuasion, social influence and aversive affect. Personal and ubiquitous computing 17, 6, 1197-1210. https://doi.org/10.1007/s00779-012-0587-1

[20] Sunny Consolvo, David W. McDonald, Tammy Toscos, Mike Y. Chen, Jon Froehlich, Beverly Harrison, Predrag Klasnja, Anthony LaMarca, Louis LeGrand, and Ryan Libby. 2008. Activity sensing in the wild: A field trial of ubifit garden. In Proceedings of the SIGCHI conference on human factors in computing systems (CHI '08), 1797-1806. https://doi.org/10.1145/1357054.1357335

[21] Andy Crabtree, Alan Chamberlain, Mark Davies, Kevin Glover, Stuart Reeves, Tom Rodden, Peter Tolmie, and Matt Jones. 2013. Doing innovation in the wild. In Proceedings of the Biannual Conference of the Italian Chapter of SIGCHI (CHItaly '13), 25. https://doi.org/10.1145/2499149.2499150

[22] Michael P. Craven, Alexandra R. Lang, and Jennifer L. Martin. 2014. Developing mHealth Apps with researchers: multi-stakeholder design considerations. 
In International Conference of Design, User

Experience, and Usability, 15-24.

[23] Torbjørn S. Dahl and Maged N. Kamel Boulos. 2013. Robots in health and social care: A complementary technology to home care and telehealthcare? Robotics 3, 1, 1-21. https://doi.org/10.3390/robotics3010001

[24] Rogério DePaula. 2004. Lost in translation: A critical analysis of actors, artifacts, agendas, and arenas in participatory design. In Proceedings of the eighth conference on Participatory design: Artful integration: interweaving media, materials and practices-Volume 1 (PDC 04), 162-172. https://doi.org/10.1145/1011870.1011890

[25] Carl DiSalvo, Andrew Clement, and Volkmar Pipek. 2012. Participatory design for, with, and by communities. In International Handbook of Participatory Design. Routledge, Oxford, UK, 182209.

[26] Carl DiSalvo, Phoebe Sengers, and Hrönn Brynjarsdóttir. 2010. Mapping the landscape of sustainable HCI. In Proceedings of the SIGCHI Conference on Human Factors in Computing Systems (CHI '10), 1975-1984. https://doi.org/10.1145/1753326.1753625

[27] Steven Dow, Anand Kulkarni, Scott Klemmer, and Björn Hartmann. 2012. Shepherding the crowd yields better work. In Proceedings of the ACM 2012 conference on computer supported cooperative work (CSCW' 12), 1013-1022. https://doi.org/10.1145/2145204.2145355

[28] Brian J. Fogg. 2002. Persuasive technology: Using computers to change what we think and do. Ubiquity 2002, December, 5. https://doi.org/10.1145/764008.763957

[29] Jodi Forlizzi. 2018. Moving beyond user-centered design. interactions 25, 5, 22-23.

[30] Derek Foster, Shaun Lawson, Jamie Wardman, Mark Blythe, and Conor Linehan. 2012. "Watts in it for me?": Design implications for implementing effective energy interventions in organisations. In Proceedings of the SIGCHI Conference on Human Factors in Computing Systems (CHI '12), 2357-2366. https://doi.org/10.1145/2207676.2208396

[31] Jon Froehlich, Tawanna Dillahunt, Predrag Klasnja, Jennifer Mankoff, Sunny Consolvo, Beverly Harrison, and James A. Landay. 2009. UbiGreen: investigating a mobile tool for tracking and supporting green transportation habits. In Proceedings of the sigchi conference on human factors in computing systems, 1043-1052.

[32] David Frohlich, Simon Robinson, Kristen Eglinton, Matt Jones, and Elina Vartiainen. 2012. Creative cameraphone use in rural developing regions. In Proceedings of the 14th international conference on Human-computer interaction with mobile devices and services, 181-190.
[33] Julie Garrigues. 2017. What is the Difference between Citizen Engagement and Participation? Retrieved August 1, 2018 from https://www.citizenlab.co/blog/civicengagement/what-is-the-difference-between-citizenengagement-and-participation/

[34] Richard H. R. Harper. 2000. The organisation in ethnography-a discussion of ethnographic fieldwork programs in CSCW. Computer Supported Cooperative Work (CSCW) 9, 2, 239-264. https://doi.org/10.1023/A:1008793124669

[35] Gillian R. Hayes. 2011. The relationship of action research to human-computer interaction. $A C M$ Transactions on Computer-Human Interaction (TOCHI) 18, 3, 15. https://doi.org/10.1145/1993060.1993065

[36] Minu Hemmati. 2012. Multi-Stakeholder Processes for Governance and Sustainability: Beyond Deadlock and Conflict. Routledge.

[37] Katherine Isbister, Elena Márquez Segura, and Edward F. Melcer. 2018. Social Affordances at Play: Game Design Toward Socio-Technical Innovation. In Proceedings of the 2018 CHI Conference on Human Factors in Computing Systems, 372.

[38] Nassim Jafarinaimi, Jodi Forlizzi, Amy Hurst, and John Zimmerman. 2005. Breakaway: An ambient display designed to change human behavior. In CHI'05 extended abstracts on Human factors in computing systems (CHI '05), 1945-1948. https://doi.org/10.1145/1056808.1057063

[39] Rose Johnson, Yvonne Rogers, Janet van der Linden, and Nadia Bianchi-Berthouze. 2012. Being in the thick of in-the-wild studies: The challenges and insights of researcher participation. In Proceedings of the SIGCHI Conference on Human Factors in Computing Systems (CHI '12), 1135-1144. https://doi.org/10.1145/2207676.2208561

[40] Ekaterina Kuts. 2009. Playful user interfaces: Literature review and model for analysis. In Proceedings of the 2009 DiGRA International Conference: Breaking New Ground: Innovation in Games, Play, Practice and Theory (DiGRA '09). Retrieved from http://www.digra.org/digitallibrary/publications/playful-user-interfaces-literaturereview-and-model-for-analysis/

[41] Christopher A. Le Dantec and Sarah Fox. 2015. Strangers at the gate: Gaining access, building rapport, and co-constructing community-based research. In Proceedings of the 18th ACM Conference on Computer Supported Cooperative Work \& Social Computing (CSCW'15), 1348-1358. https://doi.org/10.1145/2675133.2675147

[42] Ann Light, Chris Frauenberger, Jennifer Preece, Paul Strohmeier, and Maria Angela Ferrario. 2018. Taking action in a changing world. Inviting Young Scientists 25,35 . 
[43] Steven Lonn, Stephen Aguilar, and Stephanie D. Teasley. 2013. Issues, challenges, and lessons learned when scaling up a learning analytics intervention. In Proceedings of the Third International Conference on Learning Analytics and Knowledge (LAK '13), 235239. https://doi.org/10.1145/2460296.2460343

[44] Ezio Manzini. 2015. Design, When Everybody Designs: An Introduction to Design for Social Innovation. MIT Press.

[45] Christina A. Masden, Catherine Grevet, Rebecca E. Grinter, Eric Gilbert, and W. Keith Edwards. 2014. Tensions in scaling-up community social media: a multi-neighborhood study of nextdoor. In Proceedings of the SIGCHI conference on Human factors in computing systems, 3239-3248.

[46] Jane McGonigal. 2015. Super Better: A Revolutionary Approach to Getting Stronger, Happier, Braver, and More Resilient. Penguin Canada, Toronto, ON.

[47] Katja Mruck and Franz Breuer. 2003. Subjectivity and reflexivity in qualitative research-The FQS issues. Forum Qualitative Sozialforschung / Forum: Qualitative Social Research 4, 2, Art. 23.

[48] Michelle Ortlipp. 2008. Keeping and using reflective journals in the qualitative research process. The Qualitative Report 13, 4, 695-705.

[49] Jennifer Preece. 2017. How two billion smartphone users can save species! interactions 24, 2, 26-33. https://doi.org/10.1145/3043702

[50] Tom Quested and Andrew Parry. 2017. Household food waste in the UK, 2015. WRAP. Retrieved from http://www.wrap.org.uk/sites/files/wrap/Household_fo od waste in the UK 2015 Report.pdf

[51] Fiona Redhead and Margot Brereton. 2009. Designing interaction for local communications: An urban screen study. In IFIP Conference on Human-Computer Interaction, 457-460.

[52] Jennifer A. Rode. 2011. Reflexivity in digital anthropology. In Proceedings of the SIGCHI Conference on Human Factors in Computing Systems (CHI '11), 123-132. https://doi.org/10.1145/1978942.1978961

[53] Yvonne Rogers. 2011. Interaction design gone wild: Striving for wild theory. Interactions $18,4,58-62$. https://doi.org/10.1145/1978822.1978834

[54] Yvonne Rogers. 2015. Playful interactions in public. In Proceedings of the 2015 Annual Symposium on Computer-Human Interaction in Play, 127-127.

[55] Yvonne Rogers, William R. Hazlewood, Paul Marshall, Nick Dalton, and Susanna Hertrich. 2010. Ambient influence: Can twinkly lights lure and abstract representations trigger behavioral change? In Proceedings of the 12th ACM international conference on Ubiquitous computing (UbiComp '10), 261-270. https://doi.org/10.1145/1864349.1864372

[56] Yvonne Rogers and Paul Marshall. 2017. Research in the Wild. Morgan \& Claypool.
[57] Michael Scaife, Yvonne Rogers, Frances Aldrich, and Matt Davies. 1997. Designing for or designing with? Informant design for interactive learning environments. In Proceedings of the ACM SIGCHI Conference on Human factors in computing systems (CHI '97), 343-350. https://doi.org/10.1145/258549.258789

[58] Ben Shneiderman. 2011. Technology-mediated social participation: The next 25 years of HCI challenges. Agenda 6761, 3-14. https://doi.org/10.1007/978-3642-21602-2_1

[59] Ben Shneiderman. 2016. The New ABCs of Research: Achieving Breakthrough Collaborations. Oxford University Press, Oxford, UK.

[60] Alessandro Soro, Margot Brereton, Anita Lee Hong, and Paul Roe. 2015. Bi-cultural content publication on a digital noticeboard: a design and cultural differences case study. In Proceedings of the Annual Meeting of the Australian Special Interest Group for Computer Human Interaction, 217-221.

[61] Lucy A. Suchman. 1987. Plans and Situated Actions: The Problem of Human-Machine Communication. Cambridge University Press, Cambridge, UK.

[62] Alex S. Taylor, Siân Lindley, Tim Regan, David Sweeney, Vasillis Vlachokyriakos, Lillie Grainger, and Jessica Lingel. 2015. Data-in-place: Thinking through the relations between data and community. In Proceedings of the 33rd Annual ACM Conference on Human Factors in Computing Systems (CHI '15), 2863-2872. https://doi.org/10.1145/2702123.2702558

[63] Nick Taylor, Keith Cheverst, Peter Wright, and Patrick Olivier. 2013. Leaving the wild: Lessons from community technology handovers. In Proceedings of the SIGCHI Conference on Human Factors in Computing Systems (CHI '13), 1549-1558. https://doi.org/10.1145/2470654.2466206

[64] Richard H. Thaler and Cass R. Sunstein. 1999. Nudge: Improving Decisions about Health, Wealth, and Happiness. Penguin Books.

[65] Krista L. Thyberg and David J. Tonjes. 2016. Drivers of food waste and their implications for sustainable policy development. Resources, Conservation and Recycling 106, 110-123. https://doi.org/10.1016/j.resconrec.2015.11.016

[66] Rob Tieben, Tilde Bekker, and Ben Schouten. 2011. Curiosity and interaction: making people curious through interactive systems. In Proceedings of the 25th BCS Conference on Human-Computer Interaction, 361-370.

[67] Rajan Vaish, Snehalkumar Neil S. Gaikwad, Geza Kovacs, Andreas Veit, Ranjay Krishna, Imanol Arrieta Ibarra, Camelia Simoiu, Michael Wilber, Serge Belongie, and Sharad Goel. 2017. Crowd research: Open and scalable university laboratories. In Proceedings of the 30th Annual ACM Symposium on User Interface Software and Technology (UIST '17), 829-843. https://doi.org/10.1145/3126594.3126648 
[68] Leena Ventä-Olkkonen, Arto Lanamäki, Netta Iivari, and Kari Kuutti. 2016. It's a pain in the... wild?:

Struggling to create conditions for emerging practices in an urban computing project. In Proceedings of the 9th Nordic Conference on Human-Computer Interaction (NordiCHI '16), Article No. 51. https://doi.org/10.1145/2971485.2971534

[69] Volkswagen. 2009. The Fun Theory. Retrieved August 2, 2013 from http://www.thefuntheory.com/

[70] Jenny Waycott, Greg Wadley, Stefan Schutt, Arthur Stabolidis, and Reeva Lederman. 2015. The challenge of technology research in sensitive settings: Case studies in "sensitive HCI." In Proceedings of the Annual Meeting of the Australian Special Interest Group for Computer Human Interaction (OzCHI '15), 240-249. https://doi.org/10.1145/2838739.2838773
[71] Etienne Wenger, Nancy White, and John D. Smith. 2009. Digital Habitats: Stewarding Technology for Communities. CPsquare, Portland, OR.

[72] Amanda M. Williams and Lilly Irani. 2010. There's methodology in the madness: Toward critical HCI ethnography. In CHI'10 Extended Abstracts on Human Factors in Computing Systems (CHI EA '10), 2725-2734. https://doi.org/10.1145/1753846.1753857

[73] Andrea Zanella, Nicola Bui, Angelo Castellani, Lorenzo Vangelista, and Michele Zorzi. 2014. Internet of Things for smart cities. IEEE Internet of Things Journal 1, 1, 22-32.

https://doi.org/10.1109/JIOT.2014.2306328 